\title{
Typo-resource: developing T\&L support materials through collaboration
}

Article

Published Version

Loveland, P., Moys, J.-L., Tollett, H. and Towriss, M. (2016) Typo-resource: developing T\&L support materials through collaboration. The Journal of Educational Innovation, Partnership and Change, 2 (1). 238. ISSN 2055-4990 doi: https://doi.org/10.21100/jeipc.v2i1.238 Available at https://centaur.reading.ac.uk/53336/

It is advisable to refer to the publisher's version if you intend to cite from the work. See Guidance on citing.

Identification Number/DOI: https://doi.org/10.21100/jeipc.v2i1.238 $<$ https://doi.org/10.21100/jeipc.v2i1.238>

Publisher: Journal of Educational Innovation, Partnership and Change

All outputs in CentAUR are protected by Intellectual Property Rights law, including copyright law. Copyright and IPR is retained by the creators or other copyright holders. Terms and conditions for use of this material are defined in the End User Agreement.

www.reading.ac.uk/centaur 
Central Archive at the University of Reading

Reading's research outputs online 


\title{
Case Studies
}

\section{Typo-Resource: developing T\&L support materials through collaboration}

\author{
Peter Loveland, Jeanne-Louise Moys, Hannah Tollett, Melissa Towriss \\ University of Reading
}

\section{Introduction}

Responding to the ways in which our graphic communication students are currently using online resources for their independent learning, the project described in this paper focuses on identifying ways in which the University of Reading Department of Typography \& Graphic Communication can support teaching and learning (T\&L) through developing a hub of online resources. The project adopts an iterative design process (after Greenberg, 1996) in which user research and evaluation informs the development of an evolving prototype rather than simply testing a user interface post development.

Using design methods to explore technology-enhanced learning (TEL) environments is not a new approach. Within design research, "researchers manage research processes in collaboration with participants, design and implement interventions systematically to refine and improve initial designs, and ultimately seek to advance both pragmatic and theoretical aims affecting practice" (Wang and Hannafin, 2005: 6). Adopting such methods is not only appropriate for a collaborative TEL design project, it also enables our student team to gain experience and skills that enhance their employability.

\section{Theoretical and practical contexts}

Graphic communication graduates need to develop a portfolio of design work that showcases their visual flair and to be skilled in a range of software programs and technological interfaces. They also need to develop critical articulation skills to enable them to discuss design work with future clients and colleagues in a professional manner. This project experiments with the conceptualisation of an online resource to support the development of these essential skills. The project also explores issues of content, usability and interface design for virtual learning environments.

Visual disciplines such as art and design have a tradition of studio-based and projectfocused teaching (Logan, 2006). Schön (1995) has applied Polanyi's (1967) tacit knowledge concept to design professions and is often cited in discussions of design pedagogy and studio learning (e.g. Ellmers, 2006; Wang, 2006). For graphic communication - a discipline and profession where tacit knowledge abounds - studio learning provides an effective environment for learning through doing, experimentation and feedback.

The studio provides a creative space for continuing and collaborative learning, critical discourse and reflection. It is often considered to mimic the workplace and Logan's (2006) research into studio teaching supports this claim. In this respect, for example, group activities for brainstorming and pitching approaches to a brief may be used as a teaching tool, tutors may provide project feedback in the manner of a design director or client and group critiques (crits) may take a similar form to project development meetings.

The studio environment also enables peer learning in more subtle ways, such as creating opportunities for casual observation of working processes and techniques. This is 


\section{Case Studies}

particularly valuable for design students who, in terms of employability, require high levels of competence in a range of specialised software programs and methods of production and crafting. Large group demonstrations may be useful introductions to new technological tools, but do not enable students to learn at their own pace or experiment with integrating technology and creative realisation. In contrast, working within a design studio enables students to extend their skills through collaboration, experimentation and observation.

For design disciplines, TEL offers particular challenges and opportunities for extending learning beyond the physical studio. For example, the range of online tutorials and technical demonstrations available on the Internet provides students with technical support for developing competence in industry-standard and emerging software. Such resources enable students to learn to use new, specialised digital design programs effectively at their own pace and share useful resources with their peers through social media. However, finding a helpful resource that addresses the relevant queries at an appropriate level of detail can be extremely time-consuming. This may exacerbate design students' inclination to focus on developing their technical skills "without embodying critical thinking and reflective learning in their learning journey" (Park and Kastanis, 2009: 12). In relation to the Jisc digital literacy framework's four stages of development (access; skills; practice; attributes and identifies), these resources tend to support "skills" acquisition, whereas the project briefs students are given focus on developing their creative and critical "practice" (Beetham, 2014).

In addition, the availability of online resources may encourage students to work in isolation rather than in the studio. Although social media are associated with dialogue, research indicates that online postings tend to focus on encouraging peers - what Manca and Ranieri (2013: 495) term "affective communication" - rather than facilitating critical discourse and reflection. Constructive criticism is more readily provided in face-to-face studio communication. Souleles (2012) presents research that indicates that graphic communication students value the face-to-face studio time they have and do not consider social network sites to be adequate substitutes for this. A survey of research into the use of Facebook in education concurs that students are often "reluctant to use it for academic purposes" (Manca and Ranieri, 2013: 488).

Social network sites enable students to share images of their own work in progress or links to sources of inspiration. However, social network sites may not provide appropriate privacy settings for sharing student work or copyrighted projects. While academic institutional online learning platforms like Blackboard address privacy issues, these interfaces have other usability issues that seem - in the light of continuing informal verbal feedback from students - to put students off from using them. For example, the necessary institutional requirements of these academic resources means that content tends to be buried within sections rather than readily accessible. These interfaces also do not provide the affordances of social media that students readily interact with, such as the ability to bookmark and 'favourite' resources, perform searches for particular materials (both within and across modules) or view resources within a predominantly visually-orientated interface. Thus, one of the motivating factors underlying our PLanT project proposal was to identify what kinds of functionality graphic communication students would like an online studio to provide, while experimenting with ways of organising and presenting content in a digital interface. 


\section{Case Studies}

\section{Aims}

The project aims are to identify the features and affordances students would like an online learning environment to provide and, in response, to develop a prototype for an online learning resource for typography students (to be called Typo-resource) through an iterative process of design and user feedback.

Typo-resource is intended to complement the use of other technology-enhanced learning tools and resources. In addition to the use of Blackboard (the University of Reading's primary online learning environment), T\&L in our department also encompasses Facebook and Typo-realjobs - a blog for reporting progress on live student projects with real clients (see http://typorealjobs.net/complete-jobs/). Student feedback indicates that, while they have reservations about the use of Facebook for departmental communication, they find the real jobs blog a useful way to report on live projects.

\section{Methods}

The project began with a series of collaborative brainstorming workshops, in which tutors and students discussed the issues that the project was intended to respond to. The workshops also considered the affordances of different e-learning platforms, social media and project management interfaces ${ }^{1}$ with a view to identifying whether an existing platform could support our needs.

These discussions led to the development of a short questionnaire. The questionnaire explored student preferences and common methods of working and communicating among themselves and with staff. Twenty-five students completed the questionnaire. Their responses were used to identify the primary objectives and parameters of the project, providing a more focused design brief for the development of Typo-resource. In particular, the findings highlighted that students would like an online resource bank and would prefer the Department to reduce tutors' use of social media for providing resources and information.

An initial wireframe was proposed for the online resource (see Figure 1) and translated into an interactive prototype (see Figure 2). User feedback on the prototype, from both tutors and students, is being collected through a series of one-to-one, semi-structured qualitative interviews. To date, the interviews have focused on discussing what participants say they want the resource to provide, their perceptions (in relation to the prototype) of how useful the resource will be, and their suggestions for its on-going development and implementation. Twenty students and three tutors have participated in these.

The feedback is being used to refine the prototype and produce further iterations for user feedback.

\footnotetext{
${ }^{1}$ Subsequently, members of our team have used Trello as a project management tool while we work on the development of bespoke resources for Typo-Resource.
} 
Case Studies

Figure 1. Typo-resource wireframe
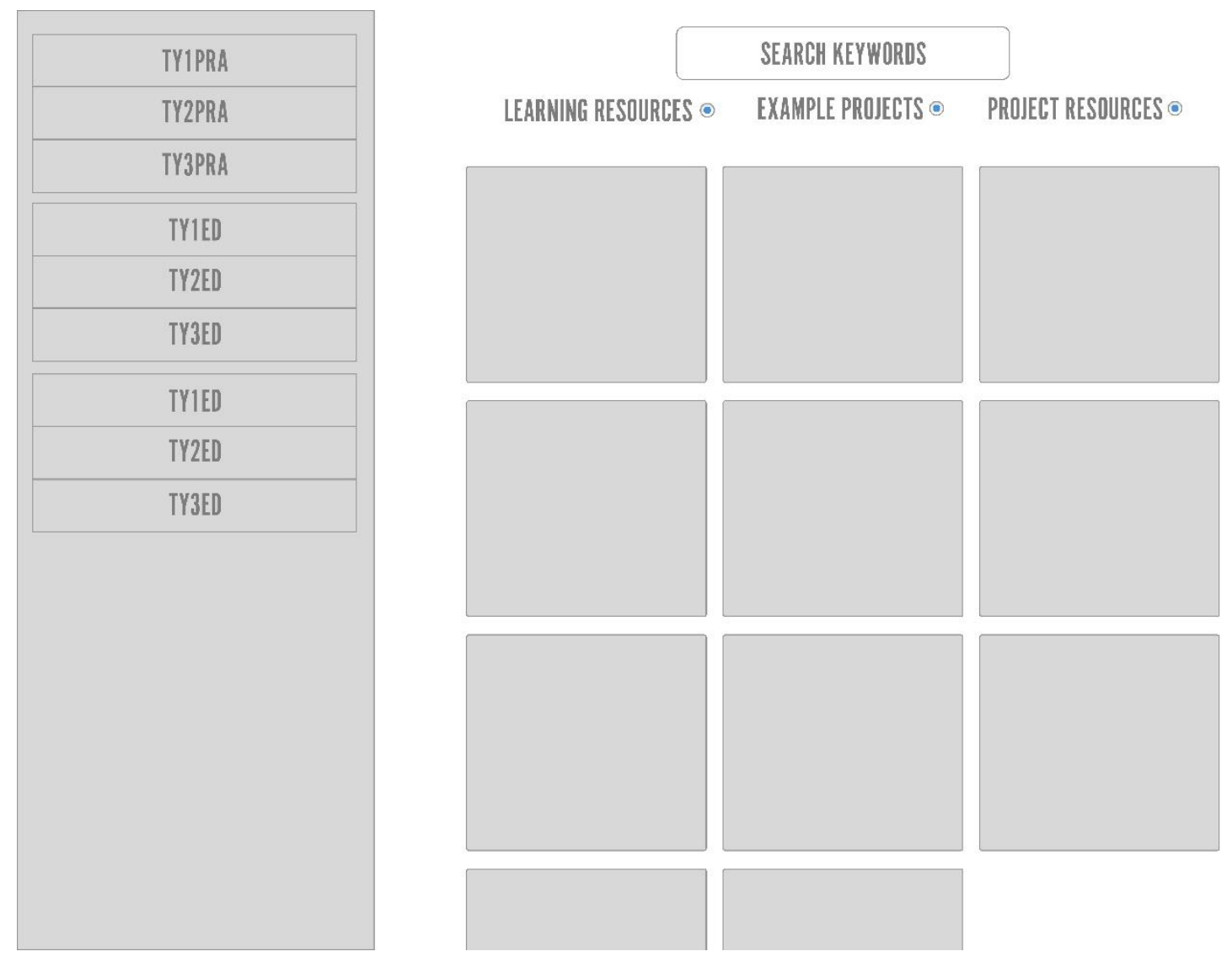

Figure 2. Screenshot of initial prototype for Typo-resource

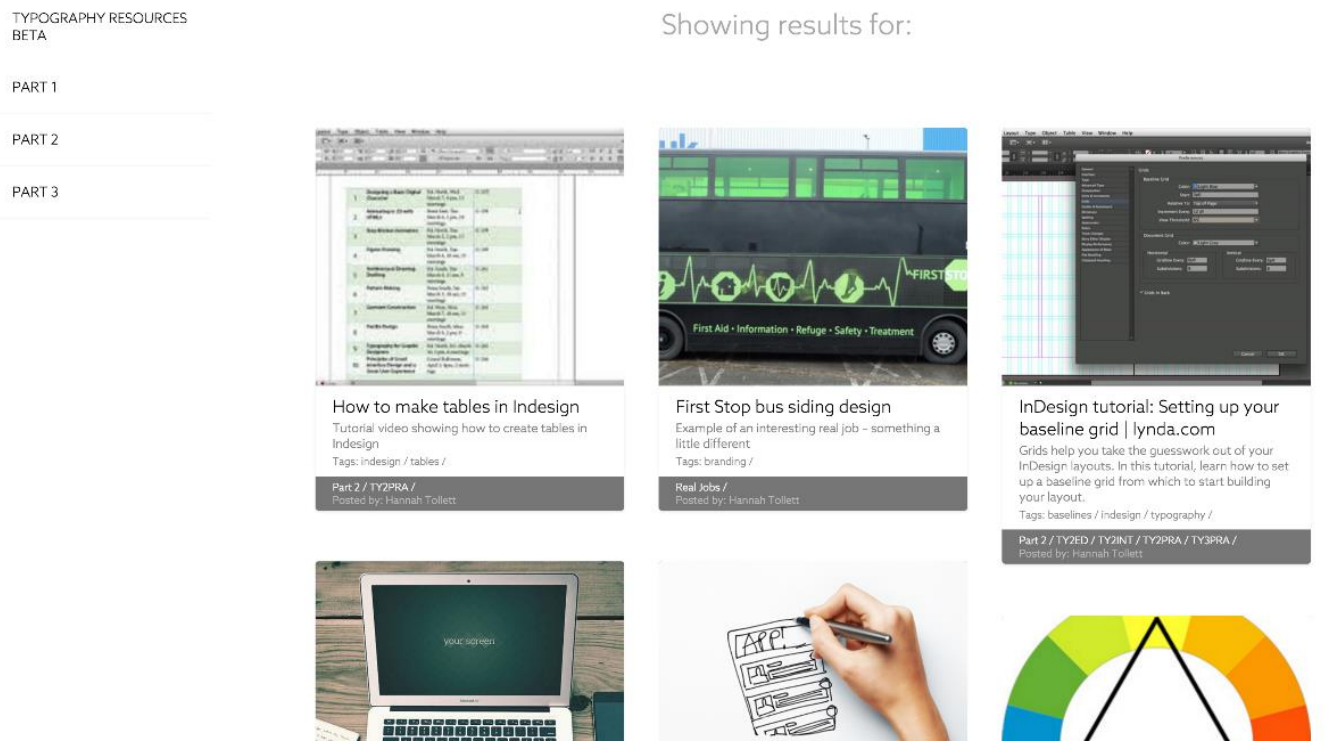




\section{Case Studies}

\section{Findings}

As we had anticipated, despite Facebook's popularity as a social tool, our students prefer to keep their academic and personal online lives separate. However, our students are keen to interact with a graphic communication-focused resource bank that can be accessed 24/7. Their ideal is a searchable interface that works well on both desktop and mobile platforms and that includes video resources.

Drawing on the data from the questionnaire, we aimed to develop a resource that prioritised navigation. Our user research has highlighted that our students want to be able both to browse information through a clear, well-structured set of categories and to search for specific resources using defined search terms.

The organisation of the content was initially structured to reflect the schedule of how the course is taught (see Figures 1 and 2). However, students should also be able to search for different tags when looking for specific resources. Our subsequent user testing has indicated that structuring by 'lesson plans' may be restrictive, because students need to experiment with new and alternative ideas for project briefs. By altering the structure, we hope to enable exploration and avoid the possibility that students might perceive particular resources as too advanced or too basic simply because they are associated with a particular module.

In terms of visual interface design, our initial research has indicated that the current interfaces of both Blackboard and Facebook do not handle information in ways that would enable students to interact with resources as they would like. Our finding is in line with those from a study conducted across a wider pool of students at the University (Parslow et al, 2008). However, our study was focused more on particular design attributes of these user interfaces, rather than on aspects of community building in e-learning (c.f. Buzzetto-More, 2012). For example, student participants in our study expressed frustration with previewing and opening documents in both interfaces, suggesting that they would like a clear preview function and files to open consistently in a pop-up window (rather than within the main interface). Blackboard, in particular, has a very complex navigation system, which the students participating in the questionnaire said they find confusing. While social networking sites are assumed to have more user-friendly interfaces, Facebook does not easily enable students to revisit or locate resources as they become buried in a linear series of posts over time. In contrast, interfaces like Pinterest that are designed to help users navigate through a lot of resources over time provide useful examples of filtering systems that we could adopt for our prototype. The Pinterest-styled collection of 'visual cards' seems to be an efficient visual structure to inform the design of our new resource.

The kinds of content we are introducing, based on feedback from the user research, include examples of good practice from both professional and student work, internet-based resources identified as relevant by either staff or students and customised resources created by both staff and students.

The initial prototype focused on practical and technical resources. However, our user research has indicated that students would like it to include both practical and theoretical resources, providing them with an integrated learning space with everything in one place. The perception seemed to be that a centralised resource would be particularly useful for first year undergraduates, who are being introduced to a range of professional, technical and 


\section{Case Studies}

theoretical skills and require clear guidance to help focus their independent learning (particularly in relation to learning to use new software).

Our findings also suggest that students would value an interface that would enable them to find trustworthy and recommended resources quickly. They see the prototype as a good point of departure for independent learning, but particularly value knowing what resources tutors and peers recommend. One of the considerations we need to explore further is whether it is important to maintain a distinction between resources identified and curated by staff and those added by students.

Typo-resource is envisaged not only as a resource bank but also as an online space for sharing work and engaging in peer feedback. Adding in the ability to 'favourite', tag and comment on resources will be important affordances in this regard. However, we need to explore a variety of ways of developing and sustaining discussion and critique so that Typoresource does not simply function as a repository.

Staff feedback suggests that we should ensure that the resource creates clear links between resources, to help students make appropriate connections, and enables navigation that is thematic rather than defined by the degree structure. Tutors agree that this resource will enable them consistently and continuously to share links with students, while ensuring that the links are saved and searchable. They also suggest that it could be useful for showcasing examiners' awards and other accolades.

\section{Discussion}

This project investigates, develops and evaluates T\&L resources that contribute to the development of shared learning through digital platforms. As a student-led project, it responds directly to the challenges that students experience currently (examples include learning to use new software and developing employability for entry into a competitive industry) and seeks to develop a platform that will support independent learning and the collaborative acquisition of skills and confidence.

This project has provided the student team with experience of conducting user research and how this can be implemented in the conceptualisation, development and evaluation of user interface design. It has also given them an opportunity to develop transferable skills including project management, teamwork and written and verbal communication through proposals, reports and presentations.

\section{Moving forward}

The project aligns effectively with the University's T\&L priorities such as TEL, employability and creating a collaborative experience. Implementation of Typo-resource, particularly if it is packaged as part of an online suite of resources for typography students, could also contribute to furthering students' sense of a bespoke 'University of Reading experience' through the development of a customised interface to support their self-directed and collaborative learning.

Based on the positive feedback on the prototype from both staff and students, we are seeking ways of implementing this resource for our students and continuing the iterative process of combining design and user research. Our main challenge will be to explore ways 


\section{Case Studies}

of developing reflection and critique regarding resources to support critical-thinking and problem-solving skills. Our intention is to continue developing and evaluating the prototype in relation to content, structure and navigation and then shift our focus to explore how to ensure the user experience enables and encourages students to engage in critical reflection and dialogue.

Whilst, in the short term, implementation is likely to be focused at a departmental level, we hope the project encourages others within our institution and across our discipline to consider opportunities to work collaboratively to support TEL. To this end, the team presented the project at the University of Reading Teaching \& Learning Showcase in March 2015 and have contributed to internal T\&L blogs.

\section{Acknowledgements}

This project was funded as part of the Partnerships in Learning and Teaching (PLanT) scheme at the University of Reading. The scheme funds small-scale initiatives that involve collaboration between staff and students at the University for enhancing T\&L.

\section{Reference list}

Beetham, H. (2014) 'Literacies development framework.' Jisc: The Design Studio:

Developing your digital literacies. Available at:

http://jiscdesignstudio.pbworks.com/w/file/67486675/Literacies\%20development\%20framew ork\%20new.doc (Accessed: 27 November 2015).

Buzzetto-More, N. A. (2012) 'Social networking in undergraduate education.' Interdisciplinary Journal of Information, Knowledge, and Management, 7, 63-90.

Ellmers, G. (2006). 'Reflection and graphic design pedagogy: developing a reflective framework to enhance learning in a graphic design tertiary environment.' 2006 ACUADS Conference: Thinking the future: Art, Design and Creativity. Melbourne: Faculty of Art \& Design, Monash University \& School of Art, Victorian College of the Arts.

Greenberg, S. (1996) 'Teaching Human Computer Interaction to Programmers.' Research report 96/582/02, Department of Computer Science, University of Calgary.

Logan, C. D. (2006) 'Circles of practice: educational and professional graphic design.' The Journal of Workplace Learning, 18(6), 331-343.

Manca, S. and M. Ranieri (2013) 'Is it a tool suitable for learning? A critical review of the literature on Facebook as a technology-enhanced learning environment.' Journal of Computer Assisted Learning, 29, 487-504.

Park, J. Y. and L. Kastanis (2009) 'Reflective learning through social network sites in design education.' The International Journal of Learning 16(8), 11-21.

Parslow, P., Lundqvist, K. Ø., Williams, S., Ashton, R. and Evans, M. (2008) Facebook \& Blackboard: comparative view of learning environments. In: SSE Systems Engineering Conference 2008, 25-26 September 2008, The University of Reading.

Polanyi, M. (1967) The tacit dimension. London: Routledge and Kegan Paul Ltd. 
Schön, D. A. (1995) The reflective practitioner: how professionals think in action. Aldershot: Arena.

Souleles, N. (2012) 'Perceptions of undergraduate graphic design students on the educational potential of Facebook.' Research in Learning Technology, 20, 241-253.

Wang, T. (2010) 'A New Paradigm for Design Studio Education.' International Journal of Art \& Design Education, 29, 173-183.

Wang, F. and M. J. Hannafin (2005) 'Design-based research and technology-enhanced learning environments.' Educational Technology Research and Development, 53(4), 5-23. 